\title{
Effects of some polyene antibiotics on human platelets and their function
}

Citation for published version (APA):

van der Plas, P. M., Kraan, L., Stibbe, J., \& Hemker, H. C. (1972). Effects of some polyene antibiotics on human platelets and their function. Haemostasis, 1972/1973(3/4), 175-190.

https://doi.org/10.1159/000213984

Document status and date:

Published: 01/01/1972

DOI:

10.1159/000213984

Document Version:

Publisher's PDF, also known as Version of record

\section{Please check the document version of this publication:}

- A submitted manuscript is the version of the article upon submission and before peer-review. There can be important differences between the submitted version and the official published version of record.

People interested in the research are advised to contact the author for the final version of the publication, or visit the DOI to the publisher's website.

- The final author version and the galley proof are versions of the publication after peer review.

- The final published version features the final layout of the paper including the volume, issue and page numbers.

Link to publication

\footnotetext{
General rights rights.

- You may freely distribute the URL identifying the publication in the public portal. please follow below link for the End User Agreement:

www.umlib.nl/taverne-license

Take down policy

If you believe that this document breaches copyright please contact us at:

repository@maastrichtuniversity.nl

providing details and we will investigate your claim.
}

Copyright and moral rights for the publications made accessible in the public portal are retained by the authors and/or other copyright owners and it is a condition of accessing publications that users recognise and abide by the legal requirements associated with these

- Users may download and print one copy of any publication from the public portal for the purpose of private study or research.

- You may not further distribute the material or use it for any profit-making activity or commercial gain

If the publication is distributed under the terms of Article $25 \mathrm{fa}$ of the Dutch Copyright Act, indicated by the "Taverne" license above, 


\title{
Effects of Some Polyene Antibiotics on Human Platelets and their Function
}

\author{
P. M. van der Plas, L. Kraan, J.Stibbe and H. C. Hemker \\ Division of Haemostasis and Thrombosis, University Hospital Dijkzigt, Rotterdam, \\ and Laboratory of Cardiovascular and Blood Coagulation Biochemistry, \\ Department of Internal Medicine, University Hospital Leiden, Leiden
}

\begin{abstract}
Polyenes aggregate platelets. The aggregation power diminishes in the following order: filipin $>$ nystatin $>$ etruscomycin pimaricin. (2) In the case of filipin, aggregation is probably caused by damage to platelets resulting in a release of platelet contents, which subsequent aggregates the remaining platelets. (3) Filipin-induced aggregation can be partially inhibited by adenosine and is $\mathrm{Ca}^{++}$-dependent. (4) Collagen- and ADP-induced

Key Words Polyene antibiotics Blood platelets Platelet aggregation Platelet factor 3

Serotonin uptake aggregation can be inhibited by low concentrations of etruscomycin. (5) Polyenes are able to release platelet factor 3 from thrombocytes. The strength decreases in the following order: filipin $>$ nystatin $>$ etruscomycin $>$ pimaricin. (6) The uptake of serotonin by platelets is diminshed by polyenes. Leakage of ${ }^{86} \mathrm{Rb}$ from preloaded platelets increases upon addition of polyenes.
\end{abstract}

Polyene antibiotics have effects upon lipid systems including monoand bilayers [7, 9, 24], liposomes [15] and the membranes of cells of sensitive organisms (yeast [3]) and erythrocytes [14]. Furthermore, lipid-dependent blood coagulation reactions are hampered by some of them [20].

The effect produced depends on several parameters including polyene: lipid ratio and the (chole)sterol content of the lipid. In low concentrations, polyenes affect only those lipid structures which contain sterols. Higher polyene: lipid ratio also cause a non-specific interaction with other lipids in some systems [8, 22]. Lytic concentrations of filipin cause the formation of pits in erythrocyte membranes [16]. It seems that polyenes bind to a component of the surface of a cell; the amount of polyene bound depends on the cholesterol content of the membrane.

Received: October 16, 1972; accepted: February 23, 1973. 
Platelets contain sterol in their membrane and in various subcellular structures. The purpose of this paper is to describe the influence of some polyenes on platelets and on a number of platelet function tests.

\section{Materials and Methods}

Polyene antibiotics were obtained from the following sources: flipin complex ( $\mathrm{M}=$ 654), referred to as 'filipin' from The Upjohn Company, Kalamazoo, Mich.; nystatin ( $M=932)$ from Labaz, Brussels, Belgium; etruscomycin $(M=700)$ from Farmitalia, Milan, Italy; pimaricin $(M=681)$ from Mycofarm, Delft, Holland.

Polyene suspensions were prepared as already described [20]. Platelett-rich plasma was obtained by collecting $5 \mathrm{ml}$ samples of blood in $0.1 \mathrm{ml} 0.55 \mathrm{M}$ citrate solution and centrifuging for $5 \mathrm{~min}$ at $400 \mathrm{~g}$. Platelet-rich plasma was used between $30 \mathrm{~min}$ and $5 \mathrm{~h}$ after centrifugation. EDTA platelet-rich plasma was obtained from blood collected in tubes containing 2-5 $\mathrm{mg}$ EDTA $/ \mathrm{ml}$ blood and treated as above.

Aggregation of platelets was measured at $37^{\circ} \mathrm{C}$ with a Vitatron photometer (VC 200) at $596 \mathrm{~m}$. Aliquots of $1.8 \mathrm{ml}$ platelet-rich plasma were incubated for 3 min in a round bottom siliconized cuvette with a magnetic stirrer. The optical density was reconded continuously by a Vitatron recorder. Paperspeed $1 \mathrm{~cm} / \mathrm{min}$. After pre-incubation $0.2 \mathrm{ml}$ of aggregating substance was added and the optical density recorded for $10 \mathrm{~min}$.

The influence of polyenes on ADP and collagen-induced platelet aggregation was measured as follows: aliquots of $1.8 \mathrm{ml}$ platelet-rich plasma were warmed in the cuvette for $3 \mathrm{~min}$ and then $0.2 \mathrm{ml}$ polyene suspension (or control solution) was added. After $10 \mathrm{~min} 0.2 \mathrm{ml}$ ADP solution (final concentration $1 \mu \mathrm{g} / \mathrm{ml}$ ) or collagen suspension was added and the optical density was recorded for another $10 \mathrm{~min}$.

ADP (obtained from Sigma) was dissolved in saline and stored at $-20^{\circ} \mathrm{C}$ in a concentration of $50 \mu \mathrm{g} / \mathrm{ml}$. Before use it was again diluted with saline to obtain a final concentration in the test mixture of $1 \mu \mathrm{g} / \mathrm{ml}$.

Collagen from human tendon was suspended in buffered-saline (1 part veronal acetate buffer, 19 parts saline) as described by RENAUD et al. [21], and was stored in frozen condition $\left(-20^{\circ} \mathrm{C}\right)$. A $1: 5$ dilution was able to aggregate the platelet-rich plasma deriving from normal individuals.

For the visual inspection of platelet aggregation a Zeiss microscope with phasecontrast equipment was used.

${ }^{86} \mathrm{Rb}$ efflux from platelets was measured as described by BAADENHUYSEN [2] with some slight modifications. The complete procedure was as follows:

(a) For the effect of polyenes present during loading on the efflux of ${ }^{3} \mathrm{Rb}\left({ }^{86} \mathrm{RbCl}\right.$ Amersham, containing $0.39 \mathrm{mg} \mathrm{Rb} / \mathrm{ml}$ with a specific activity of $1-1 / 2 \mathrm{mC} / \mathrm{ml}$ ): to $9 \mathrm{vol}$ platelet-rich plasma containing $4 \times 10^{11}$ platelets $/ 1$ and ${ }^{86} \mathrm{Rb}$ (final concentration $2 \mu \mathrm{g} / \mathrm{ml}$ ) $1 \mathrm{vol}$ of polyene suspension (or control solution) was added. Incubation of the mixture for $90 \mathrm{~min}$ at $37^{\circ} \mathrm{C}$ was followed by transfer of $1-\mathrm{ml}$ samples into dialysis bags. These bags were dialysed against $10 \mathrm{ml}$ of a modified Krebs-Ringer buffer solution (composition, mmol/1: $\mathrm{Na}^{+} 142 ; \mathrm{K}^{+} 3 ; \mathrm{Cl}^{-}{ }^{-118} ; \mathrm{HCO}_{3}-23 ; \mathrm{HPO}_{4}{ }^{2-} 1.62 ; \mathrm{H}_{2} \mathrm{PO}_{4}{ }^{-} 0.39$; glucose 22.2 ; $\mathrm{pH}$ 7.3-7.5) in a glass tube at room temperature under continuous mixing by rotation of 
the tube at $30 \mathrm{rpm}$ around its axis. After 3, 6, 10, $15 \mathrm{~min}$ and every $15 \mathrm{~min}$ thereafter for 3-4 $\mathrm{h}$, the bags were transferred to fresh tubes. The radioactivity in the glass tubes was counted with a $\gamma$-spectrometer (Packard instruments, type 5212) using 2 or $4 \mathrm{ml}$ samples. From these values the residual radioactivity after each transfer could be calculated and a time-efflux curve constructed.

(b) For the effect of polyene added during dialysis: to platelet-rich plasma containing $4 \times 10^{11}$ platelets $/ 1$ was added $2 \mu \mathrm{g}{ }^{86} \mathrm{RbCl} / \mathrm{ml}$ and after $90 \mathrm{~min}$ of incubation at $37^{\circ} \mathrm{C} 1-\mathrm{ml}$ aliquots were transferred to dialysis bags. These bags were brought into fresh glass tubes containing $10 \mathrm{ml}$ modified Krebs-Ringer solution at times as indicated above. After $60 \mathrm{~min} 0.15 \mathrm{ml}$ polyene suspension was added and the dialysis resumed for $2-3 \mathrm{~h}$. The radioactivity was measured (see above) and a time-efflux curve constructed.

Platelet factor 3 measurements were performed as follows: 1 vol platelet-rich citrated plasma and $1 \mathrm{vol}$ polyene suspension were incubated for $1 \mathrm{~min}$ at $37^{\circ} \mathrm{C}$ after which $0.1 \mathrm{ml}$ of this mixture and 0.1 Russells' viper venom (final concentration $1.7 \times 10^{-3} \mathrm{mg} / \mathrm{ml}$ ) were combined at $37^{\circ} \mathrm{C}$. After $1 \mathrm{~min} 0.1 \mathrm{ml} \mathrm{CaCl} 21 / 40 \mathrm{M}$ was added and the clotting time measured. For the estimation of total platelet factor 3, platelet-rich plasma was frozen $\left(-20^{\circ} \mathrm{C}\right)$ and thawed 4 times before incubation with polyene. Veronal-acetate buffer $(\mathrm{pH}$ 7.35) was prepared according to MichaELis [18].

Serotonin uptake by platelets in the presence of filipin was measured as follows: $1 \mathrm{ml}$ platelet-rich plasma was incubated with 5-hydroxytryptamine-creatine sulphate $(1 \mu \mathrm{g} / \mathrm{ml}$ plasma $)$ at $37^{\circ} \mathrm{C}$ and samples were taken every $5 \mathrm{~min}$ for $30 \mathrm{~min}$. These samples were centrifuged for $2 \mathrm{~min}$ at $12,000 \mathrm{~g}$ and the serotonin in the supernatant fluid was measured as described by HARDEMAN et al. [10]. The amount that had been taken up during a 30 -min period was then calculated.

\section{Results}

\section{Polyenes as Aggregation Inducers}

Polyene antibiotic suspensions were used to produce aggregation as measured with a photometer and continuous recorder. In this system changes of optical density can have two causes, since both lysis and aggregation of platelets result in a decrease of optical density. This means that a shift in optical density must be checked by examination with a microscope to see whether aggregates have actually formed. The patterns obtained with the recorder for citrated platelet-rich plasmas are shown in the figures 1-4 for filipin, nystatin, etruscomycin and pimaricin, respectively. From these figures it can be concluded that in the concentration range used only filipin and nystatin give platelet aggregation. For filipin, microscopical inspection showed the presence of very large platelet aggregates, the number and size depending on the polyene concentration. Nystatin also gives rise to aggregate formation, but aggregates are small even at an antibiotic concentration about 5 times higher than that of filipin. 

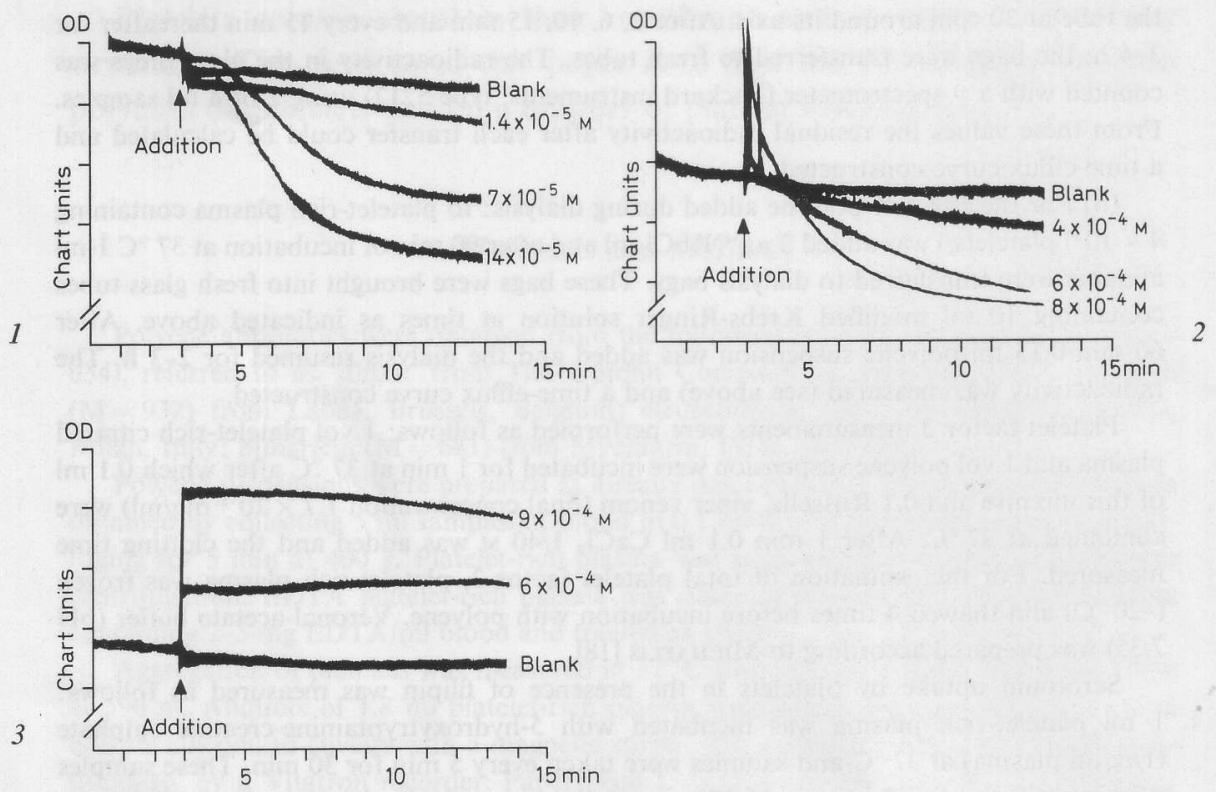

Fig. 1. Filipin-induced platelet aggregation. Vertical axis: arbitrary optical density units. Horizontal axis: incubation time. The final filipin concentrations are given to the right of the graph.

Fig. 2. Nystatin-induced platelet aggregation. Axes as figure 1.

Fig.3. Etruscomycin as a platelet aggregation inducer. Axes as figure 1.

Etruscomycin and pimaricin did not give an aggregation pattern in the concentrations applied and microscopical inspection confirmed the absence of aggregates.

In the case of filipin an optimal concentration for aggregate formation was found. At low concentrations there was an increase of the number and size of aggregates with increasing concentrations, but at concentrations higher than $\pm 2 \times 10^{-4} \mathrm{M}$ using platelet-rich plasma containing about $3 \times 10^{11}$ platelets/1 lysis of thrombocytes surpassed aggregation and at still higher concentrations $\left(5 \times 10^{-4} \mathrm{M}\right)$ aggregates could scarecely be observed with the microscope. The fall in optical density was probably caused by filipininduced lysis of platelets.

When EDTA platelet-rich plasmas were used instead of citrated plasmas in similar experiments, aggregates were never seen microscopically. The change in optical density was clearly the result of lysis of platelets. 

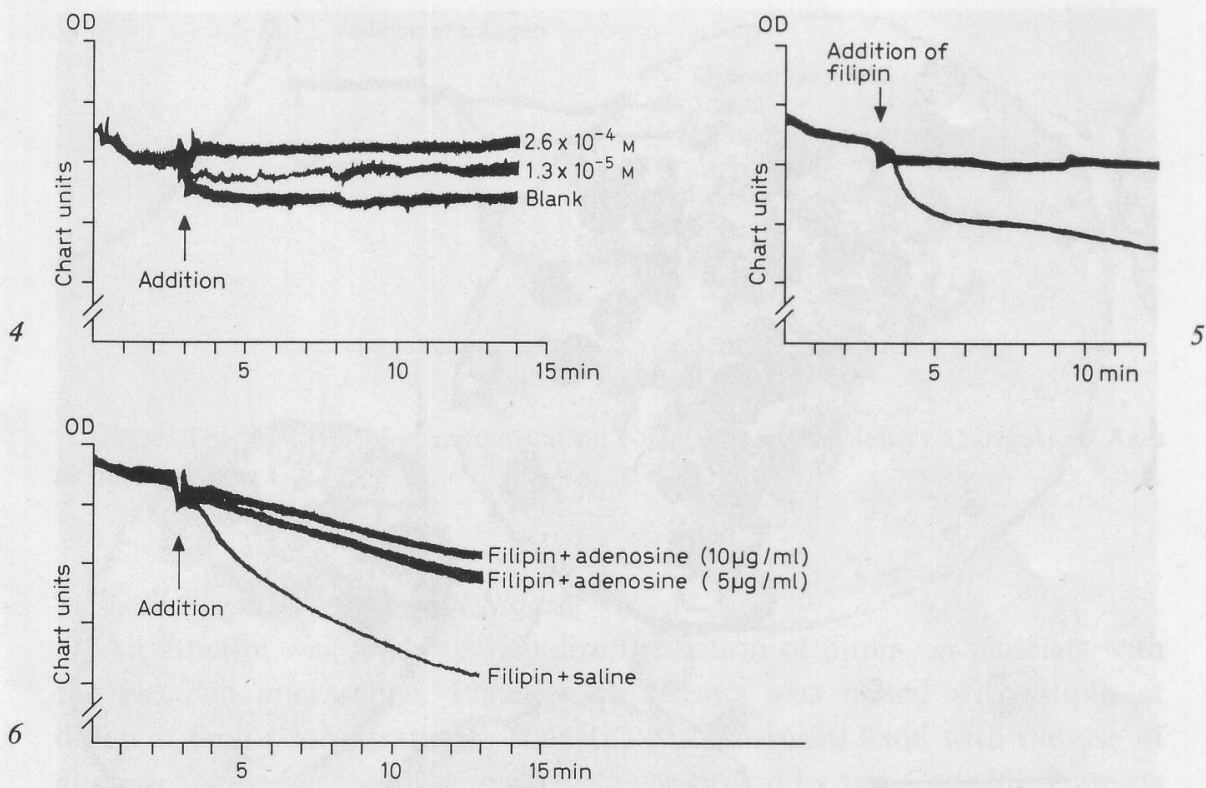

Fig.4. Pimaricin as a platelet aggregation inducer. Axes as figure 1.

Fig.5. Influence of aggregation of a filipin suspension on its ability to induce aggregation of platelets. Axes as figure 1. One part of a filipin suspension (giving a final concentration of $14 \times 10^{-5} \mathrm{M}$ ) was used directly (lower curve). Another part was centrifuged during $15 \mathrm{~min}$ at $100 \mathrm{~g}$ and the supernatant fluid was used to induce platelet aggregation (upper curve).

Fig.6. Inhibition of filipin-induced aggregation by adenosine. Axes as figure 1. Final filipin concentration $2.5 \times 10^{-4} \mathrm{M}$. Final adenosine concentrations are given to the right of the graph.

2. The Effect of Centrifugation of a Filipin Suspension on its Ability to Induce Aggregation of Platelets

The question of how the induction of aggregates takes place arises. Small particles such as kaolin can cause aggregation [4, 12, 23]. Polyene is only available in the form of a suspension of small particles which can be easily recognized with an ordinary light microscope. Aggregation might, therefore, be analogous to that caused by kaolin particles. This is not, however, likely as analogous induction of aggregation by pimaricin and etruscomycin should then also occur, since suspensions of these polyenes also contain small crystals. Centrifugation of a filipin suspension at low g-forces (15 min at $100 \mathrm{~g}$ ) greatly diminishes the aggregation power (fig. 5), so it must be 


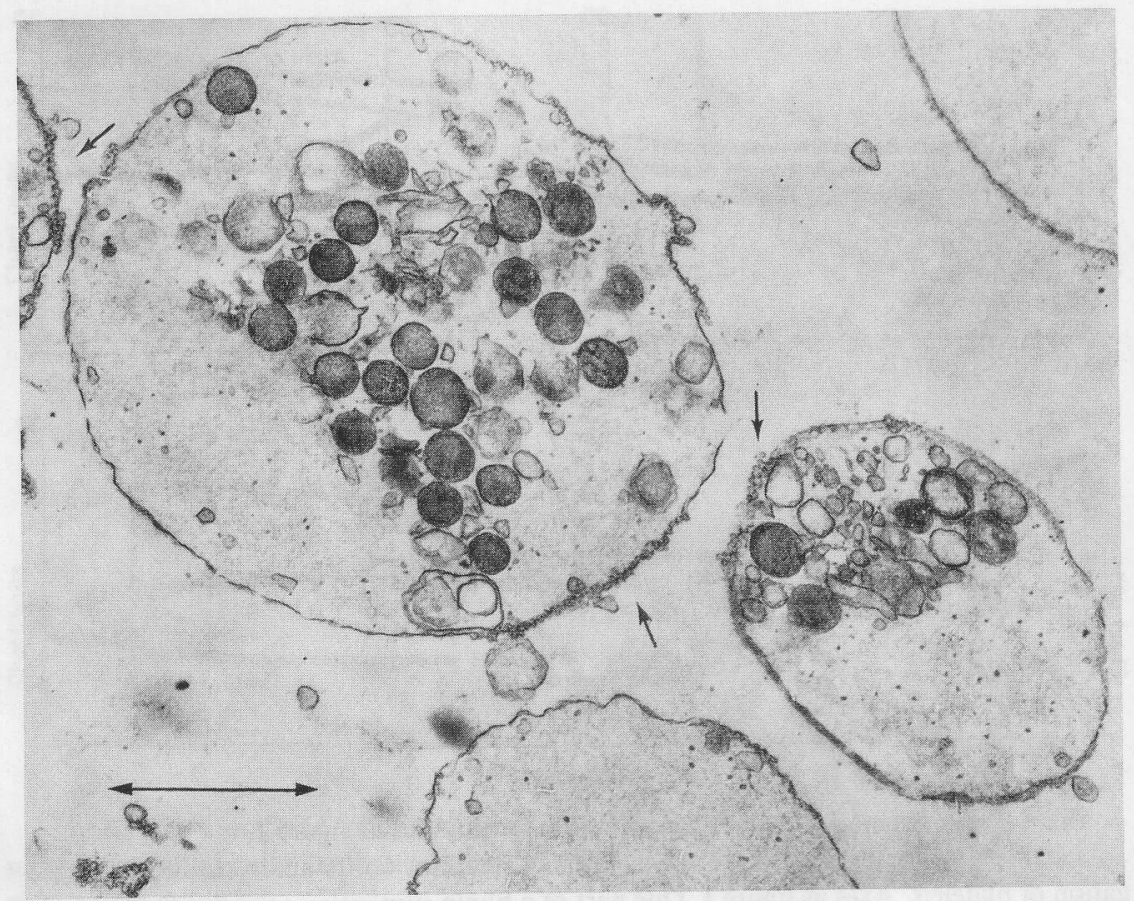

Fig.7. Electron micrograph showing the effect of filipin (final concentration $5 \times 10^{-4} \mathrm{M}$ ) on platelets. The arrow in the left corner represents $1 \mathrm{~nm}$.

assumed that aggregation indeed is caused by sedimentable particles and not by molecules in solution.

\section{The Influence of Adenosine on Filipin-Induced Aggregation of}

\section{Thrombocytes}

To determine whether the filipin-induced aggregation was mediated by release of ADP from the platelets, the influence of adenosine was looked at, since adenosine is an inhibitor of ADP-mediated platelet aggregation [5]. Various mixtures with the same concentration of filipin but increasing amounts of adenosine in saline were added to platelet-rich plasmas and the aggregation was followed both with the photometer and under the microscope.

Although a clear picture was not always obtained, it seems that this aggregation can in fact be inhibited by adenosine as can be seen from figure 6 , which shows a dose-dependent effect of adenosine. In such experiments fewer aggregates were found on inspection with the light microscope. 


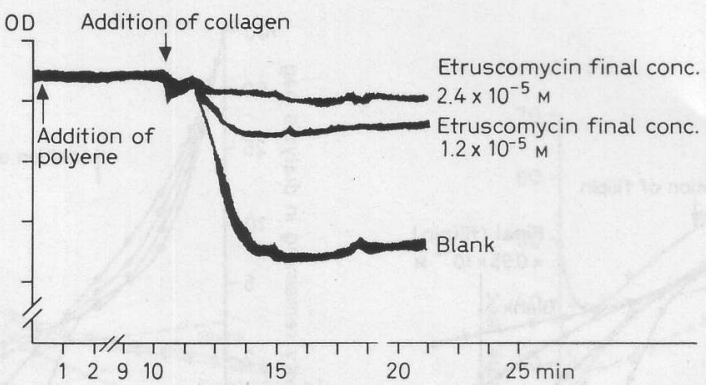

Fig. 8. The influence of etruscomycin on collagen-induced platelet aggregation. Axes as figure 1.

\section{Electron Microscopical Studies}

An attempt was made to visualize the action of filipin on platelets with the electron microscope. Platelet-rich plasma was mixed with filipin at different final concentrations. Then the platelets were fixed with the use of glutaric aldehyde according to Sixma as described by TEN CATE [6]. Platelets showed a typical EM appearance, notably with disruption of the outer membrane. Release of aggregating substances, such as ADP and serotonin, as is usually the case with damaged platelets, is suggested by these appearances.

Figure 7 showes a typical picture. It can be seen from this electron micrograph that in the case of a final concentration of filipin of $5 \times 10^{-4} \mathrm{M}$, the membranes show characteristic 'bubbles' not seen in the control. Low concentrations of filipin up to $3 \times 10^{-5} \mathrm{M}$ did not show these effects.

5. Influence of Low Concentrations of Polyenes on the ADP-and CollagenInduced Aggregation of Platelets

At polyene concentrations too small to give lysis or aggregation there might still be an interaction resulting in a diminished or enhanced aggregation of platelets induced by ADP and collagen. To investigate this possibility, the influence of polyenes on ADP and collagen aggregation was investigated in a system as described above.

If filipin is used in this test system in a final concentration too low to cause an optical density shift $\left(1.4 \times 10^{-5} \mathrm{M}\right.$ or less $)$ no influence on collagen aggregation can be observed; this is also the case with nystatin and pimaricin in maximal final concentrations of $10^{-4} \mathrm{M}$ and $1.3 \times 10^{-4} \mathrm{M}$, respectively. Etruscomycin, on the other hand, reduces the collagen-induced aggregation at final concentrations much lower than those used in the experiments described under Results No. $1\left(1.2 \times 10^{-5} \mathrm{M}\right.$ and $6 \times 10^{-4} \mathrm{M}$, respectively) (fig. 8). 

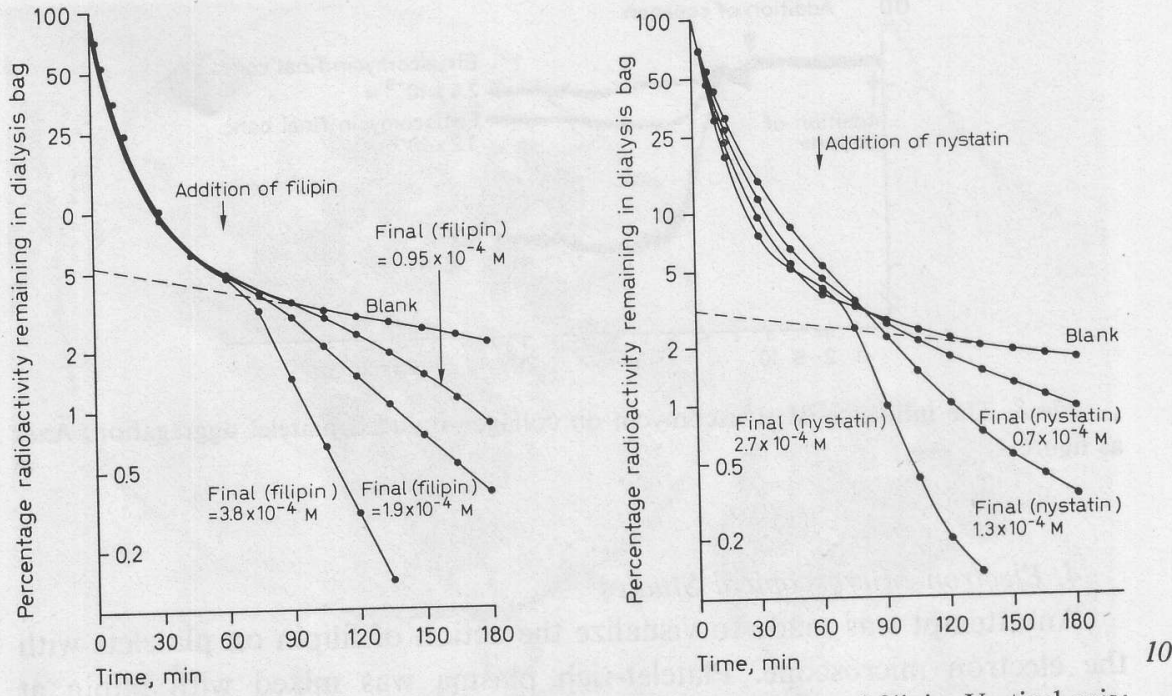

Fig.9. Efflux of ${ }^{86} \mathrm{Rb}$ from preloaded platelets in the presence of filipin. Vertical axis: percentage residual radioactivity in dialysis bag. Horizontal axis: dialysis time (min).

Fig. 10. Efflux of ${ }^{86} \mathrm{Rb}$ from preloaded platelets in the presence of nystatin. Axes as figure 9 .
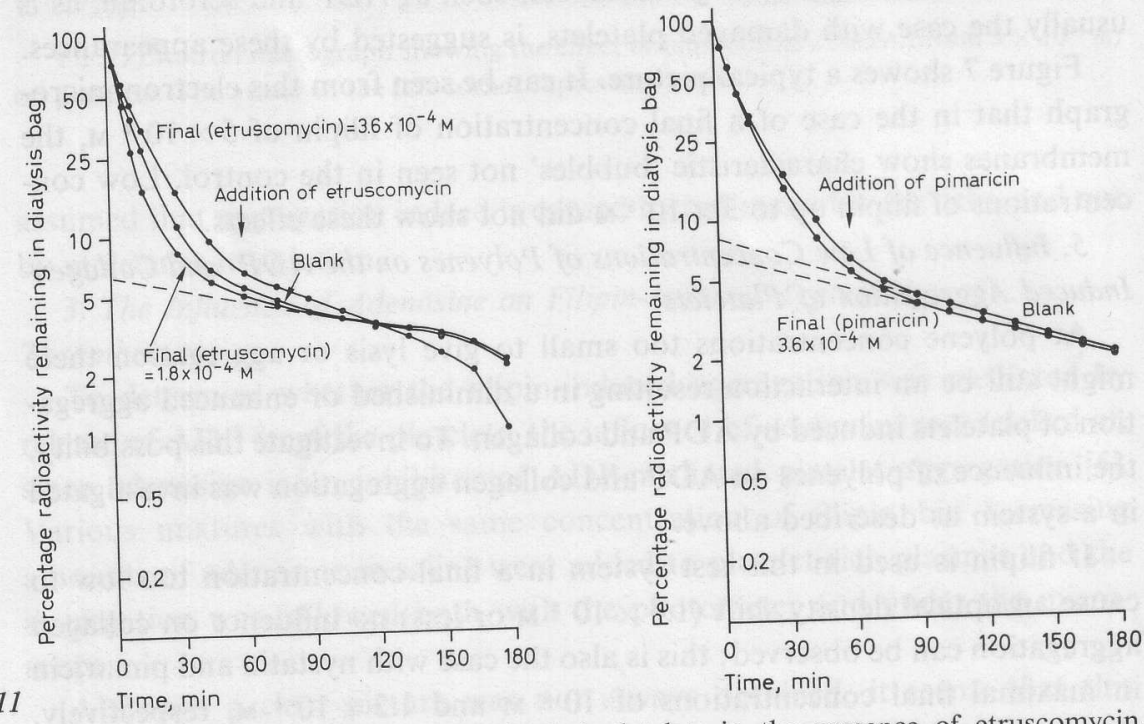

Fig.11. Efflux of ${ }^{86} \mathrm{Rb}$ from preloaded platelets in the presence of etruscomycin. Axes as figure 9.

Fig. 12. Efflux of ${ }^{86} \mathrm{Rb}$ from preloaded platelets in the presence of pimaricin. Axes as figure 9 . 

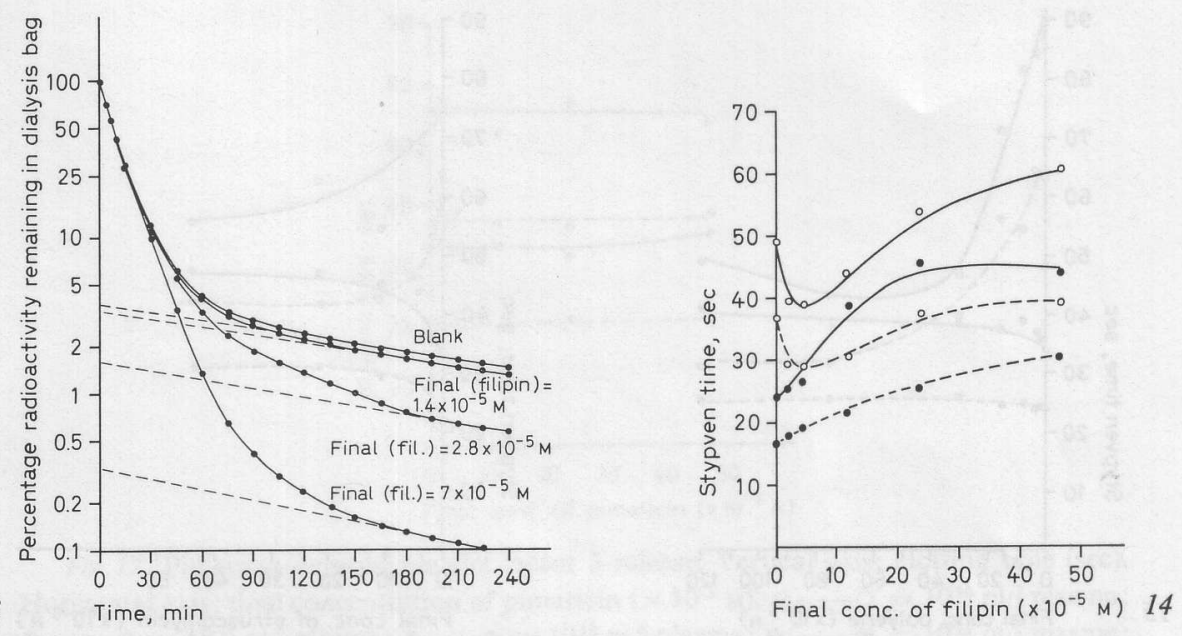

Fig. 13. Efflux of ${ }^{86} \mathrm{Rb}$ from platelets loaded in the presence of filipin. Axes as figure 9 .

Fig. 14. Filipin-induced platelet factor 3 release. Vertical axis: clotting time (sec). Horizontal axis: final concentration of filipin $\left(\times 10^{-5} \mathrm{M}\right) . \mathrm{O}-\mathrm{O}=10^{10} \mathrm{pl} / 1 \mathrm{plasma}$; $\mathrm{O}_{---} \mathrm{O}=10^{11} \mathrm{pl} / 1 \mathrm{plasma} ; \bullet-\longrightarrow=10^{10} \mathrm{pl} / 1 \mathrm{plasma} ; \bullet---\bullet=10^{11} \mathrm{pl} / 1 \mathrm{plasma}$; - = frozen and thawed 4 times.

The same effect of etruscomycin is seen upon ADP-induced aggregation (final ADP-concentration $1 \mu \mathrm{g} / \mathrm{ml}$ ) which is also markedly reduced by this antibiotic. Fewer aggregates are seen on microscopy.

6. Leakage of ${ }^{86} \mathrm{Rb}$ through the Thrombocyte Membrane in the Presence of Filipin

BAADENHUYSEN [2] described a method of measuring the leakage of ${ }^{86} \mathrm{Rb}$ from platelets which has been loaded by incubation with a $\mathrm{RbCl}$ solution. The method was slightly modified to assess the influence of polyenes present either during loading or passive leakage of ${ }^{86} \mathrm{Rb}$ through the cell membrane in the surrounding medium. Figures 9-12 show the influence of polyenes added $1 \mathrm{~h}$ after the onset of dialysis. The rate of loss of radioactivity from the dialysis bag is increased, the effect being strongest for filipin and totally absent for pimaricin. This effect is concentration dependent. In figure 13 the effect is shown of adding filipin during the loading with ${ }^{86} \mathrm{Rb}$. The total amount of ${ }^{86} \mathrm{Rb}$ loaded is calculated by extrapolation to time zero of the line found from the time that the excess of ${ }^{86} \mathrm{Rb}$ has been dialysed. The load of ${ }^{86} \mathrm{Rb}$ is clearly diminished by polyenes. The strength of the effect on the loading is filipin $>$ nystatin $>$ etruscomycin $>$ pimaricin, when equal molarities are compared. 

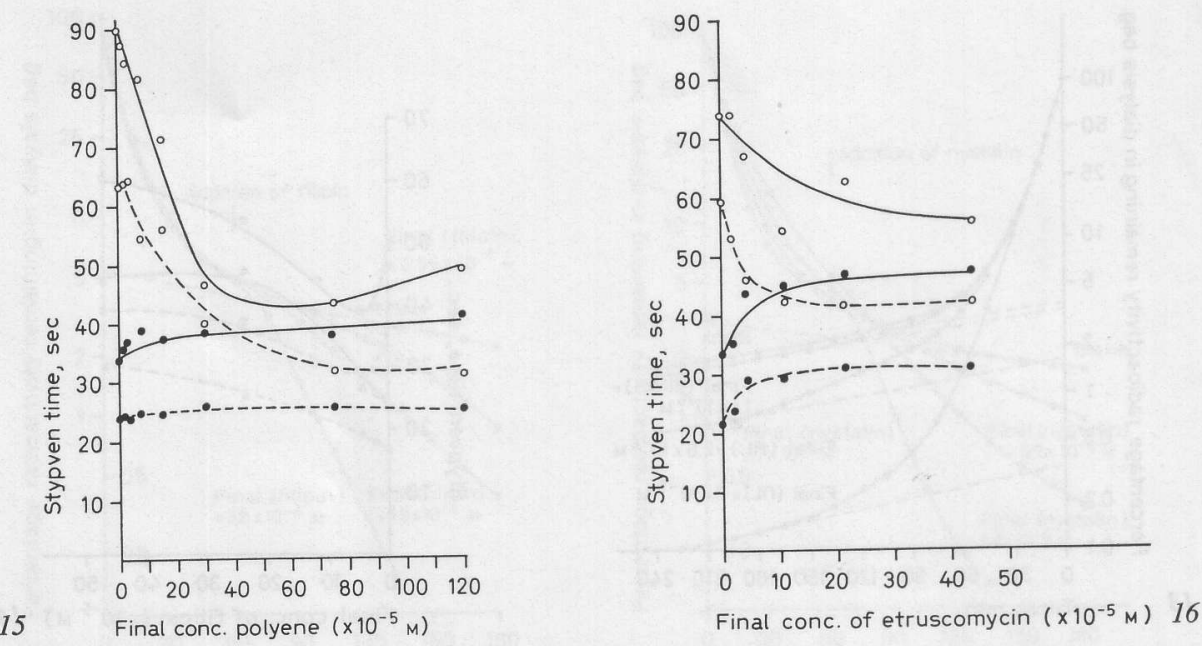

Fig.15. Nystatin-induced platelet factor 3 release. Vertical axis: clotting time (sec). Horizontal axis: final concentration of nystatin $\left(\times 10^{-5} \mathrm{M}\right) . \mathrm{O}^{-} \mathrm{O}=10^{10} \mathrm{pl} / 1 \mathrm{plasma}$; $0---0=10^{11} \mathrm{pl} / 1$ plasma;

$\bullet=10^{10} \mathrm{pl} / \mathrm{l}$ plasma; $\bullet-\ldots=10^{11} \mathrm{pl} / 1$ plasma;

- = frozen and thawed 4 times.

Fig. 16. Etruscomycin-induced platelet factor 3 release. Vertical axis: clotting time $(\mathrm{sec})$. Horizontal axis: final concentration of etruscomycin $\left(\times 10^{-5} \mathrm{M}\right) . \mathrm{O}-\mathrm{O}=10^{10} \mathrm{pl} / 1$

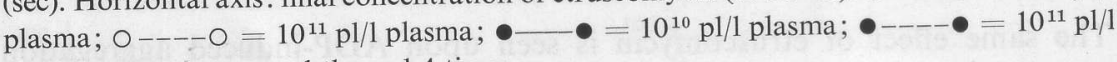
plasma; $\bullet=$ frozen and thawed 4 times.

\section{The 'Release' of Platelet Factor 3 in the Presence of Polyenes}

Many authors have described the release of platelet factor 3 from thrombocytes by processes in which disruption of thrombocytes could be expected, e.g. repeated freezing and thawing or incubation with particles such as kaolin $[11-13,23]$. The release of $\mathrm{PF}_{3}$ in the presence of polyenes was investigated using the method of SPAET and CinTRON [23], modified appropriately. Polyenes were added to platelet-rich plasmas with varying platelet count and the clotting times recorded. In each experiment platelet-free plasma from the same subject was always used for dilution so that the number of platelets was the only variable. Figures 14-17 show the effect of polyenes on clotting time. It can be seen that polyenes are in fact able to release $\mathrm{PF}_{3}$. Here too, magnitude of the effect depends upon the polyene used. As a control clotting times using an optimal amount of $\mathrm{PF}_{3}$ (so-called total $\mathrm{PF}_{3}$ ) are included in the figures. This optimal amount of $\mathrm{PF}_{3}$ was obtained by 


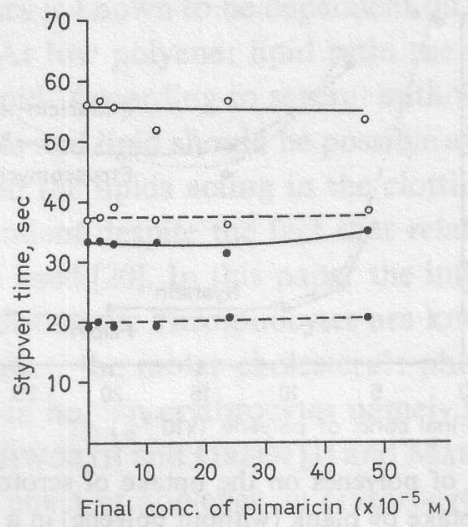

Fig. 17. Pimaricin-induced platelet factor 3 release. Vertical axis: clotting time (sec). Horizontal axis: final concentration of pimaricin $\left(\times 10^{-5} \mathrm{M}\right) .0-\mathrm{O}=10^{10} \mathrm{pl} / 1 \mathrm{plasma}$;

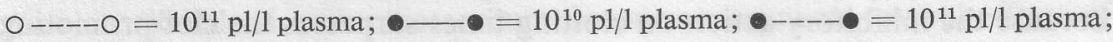
- = frozen and thawed 4 times.

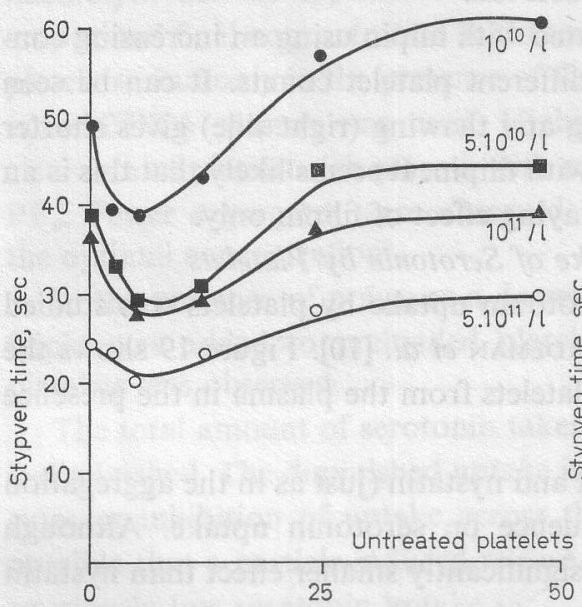

Final conc. of filipin $\left(\times 10^{-5} \mathrm{M}\right)$

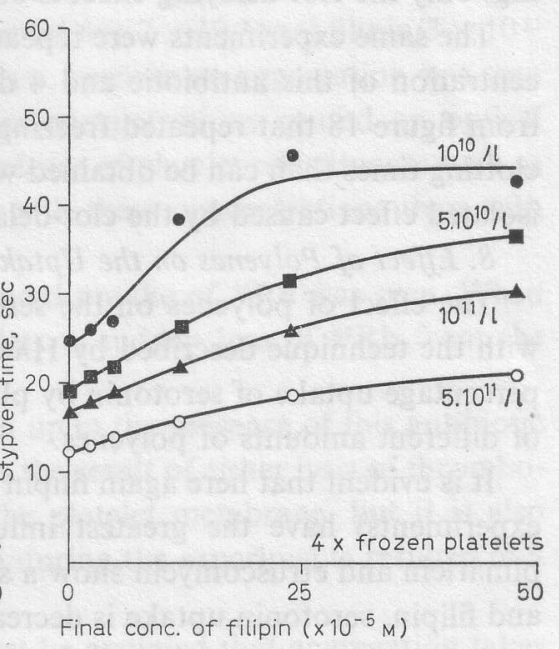

Final conc. of filipin $\left(\times 10^{-5} \mathrm{M}\right)$

Fig.18. Filipin-induced platelet factor 3 release. Vertical axis: clotting time (sec). Horizontal axis: final concentrations of filipin $\left(\times 10^{-5} \mathrm{M}\right)$. Left hand graph: untreated platelets. Right hand graph: platelets frozen and thawed 4 times.

freezing and thawing the material four times. A dual effect can be seen in these figures. At low concentrations of filipin and (to a lesser extent of etruscomycin) a shortening of clotting times is seen due to 'release' of $\mathrm{PF}_{3}$. At higher concentrations lengthening of clotting times is again observed 


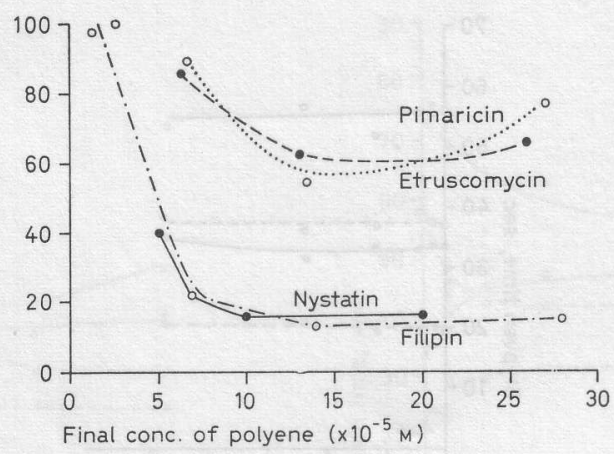

Fig. 19. The influence of polyenes on the uptake of serotonine by platelets. Vertical axis: percentage of the uptake by blank (without polyene) in a 30 -min period. Horizontal axis: final concentration of polyenes $\left(\times 10^{-5} \mathrm{M}\right)$.

because the inhibitory action on clotting times surpasses the clot-promoting effect by the release of $\mathrm{PF}_{3}$. In the case of total $\mathrm{PF}_{3}$ (after freezing and thawing) only the clot-delaying effect is observed.

The same experiments were repeated with filipin using an increasing concentration of this antibiotic and 4 different platelet counts. It can be seen from figure 18 that repeated freezing and thawing (right side) gives shorter clotting times than can be obtained with filipin. It seems likely that this is an isolated effect caused by the clot-delaying effect of filipin only.

\section{Effect of Polyenes on the Uptake of Serotonin by Platelets}

The effect of polyenes on the serotonin uptake by platelets was studied with the technique described by HaRdeman et al. [10]. Figure 19 shows the percentage uptake of serotonin by platelets from the plasma in the presence of different amounts of polyenes.

It is evident that here again filipin and nystatin (just as in the aggregation experiments) have the greatest influence on serotonin uptake. Although pimaricin and etruscomycin show a significantly smaller effect than nystatin and filipin, serotonin uptake is decreased by all these polyenes.

\section{Discussion}

The influence of polyene antibiotics on microorganisms and erythrocytes has been the subject of study for some years. The effects on systems such as lipid layers and liposomes have been investigated by a number of techniques based on, for instance, surface tension [7, 9], the lifetime of bilayers [24], and the transport of ions and small molecules across membranes. 
The effect of polyenes is known to be dependent on the presence of cholesterol in membranes. At low polyene: lipid ratio the effect depends on the sterol content of the lipid. According to several authors a less specific interaction between polyenes and lipid should be possible at higher polyene: lipid ratios. The influence on the lipids acting in the clotting mechanism proved to be cholesterol dependent despite the fact that relatively high concentrations of polyenes were used [20]. In this paper the influence of polyenes on the human platelet is discussed. Thrombocytes are known to contain cholesterol in their membranes, the molar cholesterol: phospholipid ratio being lower than this found in human erythrocytes namely 0.53 and 0.89 , respectively, according to AsHwORTH and GREEN [1] and MARCus et al. [17]. On the basis of this ratio, the effect of polyenes on erythrocytes can be expected to be greater than on platelets. An increased effect might occur in those cases where the (chole)sterol content of the platelet is higher than in normal platelets (if indeed such cases occur). In our experiments several effects of polyenes on platelets were found. The most potent polyene (on basis of its haemolytic action) appears to be able to induce aggregation of platelets if an optimal final concentration is chosen (about $2 \times 10^{-4} \mathrm{~mol}$ filipin $/ 3 \times 10^{11}$ platelets), but only in the presence of $\mathrm{Ca}^{++}$, because no aggregation was seen when EDTA plasma was used. Higher concentrations caused an optical clearance of platelet-rich plasma with release of platelet constituents such as $\mathrm{PF}_{3}$. Fewer aggregates were observed with these concentrations than with the optimal concentration.

In the presence of polyenes a decreased uptake of ${ }^{86} \mathrm{Rb}$ was seen. When filipin was added to preloaded platelets a sudden loss of ${ }^{86} \mathrm{Rb}$ from the platelets was observed.

The total amount of serotonin taken up in the presence of this antibiotic is diminished. The diminished uptake is the result of either lysis of thrombocytes or inhibition of uptake across the platelet membrane, but it is also possible that a particle-induced release during the experiments resulted in a spuriously low serotonin uptake.

On the basis of these findings it must be assumed that aggregation takes place because under optimal conditions some of the thrombocytes are lysed (or at least destroyed) resulting in aggregation of the remaining intact platelets by 'released' cell content. This hypothesis is supported by the finding that adenosine counteracted the polyene-induced aggregation.

Furthermore, the electron micrographs showed that indeed a membrane 'destruction' with possible loss of cell constituents takes place. The influence of filipin on the collagen- and ADP-induced aggregation is difficult to inter- 
pret because even when small amounts of filipin are used some lysis can not be excluded.

The other polyenes did not have such pronounced effects as filipin. Nystatin in polyene: lipid ratios higher (about 5 times) than filipin can give some aggregation, but the aggregates are always small as compared to those induced by filipin. Here too, at higher concentrations no aggregates are found. Possibly the release of aggregation-inducing substances from platelets is insufficient (too slow) to cause aggregation. However, the lysis of erythrocytes is a quick process also when nystatin is used [7]. It cannot be excluded that the difference in lipid composition between platelets and erythrocytes is the cause of a relatively low sensitivity of the platelet membrane as compared to the erythrocyte membrane. In the other tests too, such as $\mathrm{PF}_{3}$ release and clot-inhibition, nystatin seems to be a weaker agent than filipin which confirms the result of other authors [7-9] in different systems.

Pimaricin and etruscomycin did not cause aggregation in the concentrations used. Etruscomycin, however, did inhibit ADP- or collagen-induced aggregation even at low concentrations. Possibly an adsorption onto (or at least interaction with) the platelet membrane results in a hindrance of normal interaction needed for aggregation. Another possibility is that the action of etruscomycin alters the membrane and thus inhibits the release of ADP (after the collagen-platelet interaction). This is in accordance with the ideas of PACHE and CHAPMAN [19] who assume a changed fluidity of lipid chains in bilayers under such conditions. Pimaricin did not have any influence on collagen- and ADP-induced aggregation up to $2.5 \times 10^{-4} \mathrm{M}$. Also this polyene does not possess the other effects of filipin and nystatin.

All data for these 4 antibiotics together with some data from other authors are summarized in a qualitative manner in table I.

It must be stated that the order of strength of polyenes is dependent upon the test system used. Several authors point out that though all belong to the group of polyene antibiotics large differences in action can be found as a result of the molecular structure and size of the different polyenes. In the past a distinction was drawn between a high and a low molecular weight group by LAMPEN et al. with respect to their strength of influencing lipids. They proposed an inverse correlation between the number of carbon atoms and the extent of membrane damage. In general, however, it can be stated that the action of polyene antibiotics upon platelets runs parallel to that found in other test systems. 
Table I. Effect of polyene antibiotics on thrombocytes

\begin{tabular}{|c|c|c|c|c|}
\hline & Pimaricin & Etruscomycin & Nystatin & Filipin \\
\hline $\begin{array}{l}\text { Aggregation of citrated } \\
\text { platelet-rich plasma }\end{array}$ & & & + & + \\
\hline $\begin{array}{l}\text { ADP/collagen } \\
\text { aggregation }\end{array}$ & & inhibition & & 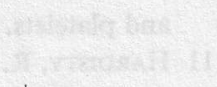 \\
\hline $\mathrm{PF}_{3}$ release & - & some & & + \\
\hline${ }^{86} \mathrm{Rb}$ leakage & & slight increase & increase & $\begin{array}{l}\text { strong increase } \\
\text { decrease }\end{array}$ \\
\hline Serotonin uptake & slight decrease & slight decrease & decrease & $\begin{array}{l}\text { decrease } \\
\text { stronginhibition }\end{array}$ \\
\hline $\begin{array}{l}\text { Coagulation } \\
\text { Monolaver surface }\end{array}$ & - & slight inhibition & & stomg \\
\hline $\begin{array}{l}\text { Monolayer surface } \\
\text { pressure [7] }\end{array}$ & slight influence & strong influence & influence & strong influence \\
\hline Bilayer lifetime [24] & slight shortening & shortening & $\begin{array}{l}\text { marked } \\
\text { shortening }\end{array}$ & $\begin{array}{l}\text { marked } \\
\text { shortening }\end{array}$ \\
\hline
\end{tabular}

\section{Acknowledgements}

The electron micrographs were produced by Dr. DE BRUYN, Laboratory of Clinical Pathology, EM Department, University Hospital Rotterdam-Dijkzigt, Rotterdam, The Netherlands. Dr. HARDEMAN (Amsterdam) and Dr. BAADENHUYSEN (Nijmegen) are thanked for help at the serotonin uptake and ${ }^{86} \mathrm{Rb}$ leakage experiments, respectively. Counting of ${ }^{86} \mathrm{Rb}$ was performed by Ing. VAN ZIJL, Department of Nuclear Medicine, University Hospital Rotterdam-Dijkzigt, Rotterdam, The Netherlands.

\section{References}

1 Ashworth, L.A.E. and Green, C.: Plasma membranes. Phospholipid and sterol content. Science 151: 210 (1966).

2 BAADENHUYSEN, H.: Platelet metabolism and membrane function; thesis Nymegen (1971).

3 BALCAVJE, W.X.; BAELE, M., et al.: Effect of filipin on rat liver and yeast mitochondria. Biochim. biophys. Acta 162: 525 (1968).

4 Bloom, G.; Gustavson K.H., and Swensson, A.: On the reaction of the thrombocytes to submicroscopic particles in vitro. Acta haemat. 13: 57 (1955).

5 BoRN, G.V.R.: Strong inhibition by 2-chloro-adenosine of the aggregation of blood platelets by adenosine diphosphate. Nature, Lond. 202: 95 (1962).

6 CATE, J.W. TEN: Platelet functions in relation to haemostasis; thesis Amsterdam, p. 42 (1971).

7 DEMEL, R.A.: Monomolecular layers of lipids; thesis Utrecht (1966). 
8 Demel, R.A.; Crombag, F.J.L.; Deenen, L.L.M. van, and Kinsky, S.C.: Interaction of polyene antibiotics with single and mixed monomolecular layers. Biochim. biophys. Acta 150: 1 (1968).

9 Demel, R.A.; Deenen, L.L.M. van, and Kinsky, S.C.: Penetration of lipid monolayers by polyene antibiotics. J. biol. Chem. 240: 2749 (1965).

10 Hardeman, M.R.; UyL, A. Den, and Prins, H.K.: A semi-mechanized method for the fluormetric determination of 5-hydroxytryptamine (serotonin) in blood plasma and platelets. Clin.chim. Acta 37: 71 (1972).

11 Hardisty, R. M. and Hutton, R.A.: The kaolin clotting time of platelet-rich plasma. A test of platelet factor 3 availability. Brit.J. Haemat. 11: 258 (1965).

12 Hardisty, R.M. and Hutton, R.A.: Platelet aggregation and the availability of platelet factor 3. Brit. J. Haemat. 12: 764 (1966).

13 Hovmand, L.L.; Brons, K., and Gorinsen, J.: Platelet phospholipid and stypven clotting time. Thromb. Diath. haemorrh. 21: 463 (1969).

14 KinsKY, S.C.: Comparative response of mammalion erythrocytes and microbial protoplasts to polyene antibiotics and vitamin A. Arch. Biochem.Biophys. 102: 180 (1963).

15 KINSKY, S. C.; HAXBY, J., et al.: Effect of cholesterol incorporation on the sensitivity of liposomes to the polyene antibiotic filipin. Biochim. biophys. Acta 152: 174 (1968).

16 Kinsky, S. C.; LuSE, S.A.; Zopf, D., and DEEnEN, L. L. M. van: Interaction of filipin and derivates with erythrocyte membranes and lipid dispersions: electron microscopic observations. Biochim. biophys. Acta 135: 844 (1967).

17 Marcus, A.J.; Ulman, H.L., and SAfier, L.B.: Lipid composition of subcellular particles of human blood platelets. J. Lipid Res. 10: 108 (1969).

18 Michaelis, L.: Der Acetat-Veronal-Puffer. Biochem.Z. 234: 139 (1931).

19 PACHE, W. and CHAPMAN, D.: Interaction of antibiotics with membranes: chlorotricin. Biochim. biophys. Acta 255: 348 (1972).

20 Plas, P. M. van DeR; KraAn, L., and Hemker, H.C.: Filipin as a tool for the study of blood coagulation reactions. Thromb. Diath. haemorrh. 27: 584 (1972).

21 Renaud, S.; Kuba, K.; Goulet, C.; Lenure, Y., and Allard, C.: Relationship between fatty-acid composition of platelets and platelet aggregation in rat and man. Circulat. Res. 26: 553 (1970).

22 Sessa, G. and WeissmanN, G.: Effect of four components of the polyene antibiotic, filipin on phospholipid spherules (liposomes) and erythrocytes. J.biol. Chem. 243: 4363 (1968).

23 SPAEt, T.H. and CINTRON, J.: Studies on platelet factor 3 availability. Brit. J. haemat. 11: 269 (1965).

24 ZutPhen, H. van: DeEnen, L. L.M. van, and Kinsky, S.C.: The action of polyene antibiotics on bilayer lipid membranes. Biochem. biophys. Res. Commun.22: 4, 393 (1966).

Request reprints from: P. M. VAN DER PLAS, Division of Haemostasis and Thrombosis, University Hospital Dijkzigt, Rotterdam (The Netherlands) 